
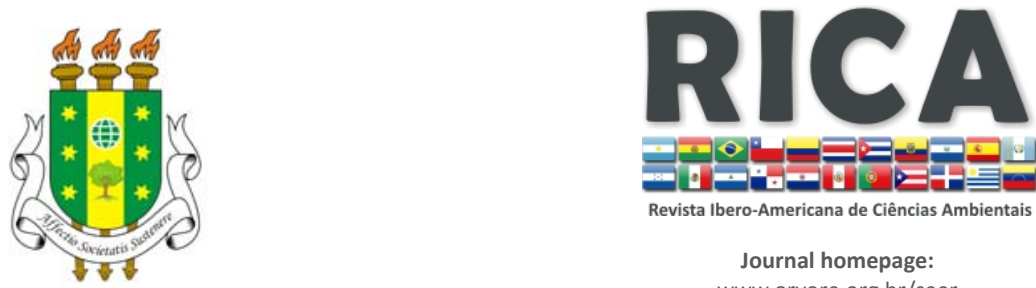

Journal homepage:

www.arvore.org.br/seer

\section{BIOCOMBUSTÍVEIS NO BRASIL: MUDANÇAS INSTITUCIONAIS, COMPETITIVIDADE E GOVERNANÇA FEDERAL}

\section{RESUMO}

Este trabalho busca avaliar o setor de biocombustíveis no Brasil sob o ponto de vista das mudanças institucionais ocorridas, seus impactos no modelo de governança e na competitividade sistêmica. Partindo do processo histórico do setor de etanol, foram utilizados os conceitos de competitividade sistêmica, de mudança institucional, equilíbrio pontuado, advocacy coalition framework (ACF) e de governança em rede para a análise do atual arranjo institucional dentro da Administração Pública Federal. A partir de entrevistas com membros do Conselho Interministerial do Açúcar e do Álcool e da Comissão Executiva Interministerial do Biodiesel, que compõem o sistema de governança federal, pode-se observar que, mesmo sendo um importante componente da matriz energética, o setor de biocombustíveis ainda não possui uma estratégia definida de forma ampla, apresentando uma ausência de articulação e fragilidade nos mecanismos de governança no âmbito federal. No setor de etanol principalmente, é constatado que o Conselho Interministerial do Açúcar e do Álcool apresenta dificuldade em estabelecer a estratégia de forma clara e principalmente de comunica-la aos demais integrantes da Administração Pública Federal. As demais bioenergias como o biogás ou a biomassa não são tratadas no âmbito destes órgãos de governança de forma sistêmica e tem ações isoladas sendo executadas de forma desarticulada pelos órgãos da Administração Pública Federal.

PALAVRAS-CHAVE: Mudança Institucional; Governança, Biocombustíveis.

\section{BIOFUELS IN BRAZIL: INSTITUTIONAL CHANGE, COMPETITIVENESS AND FEDERAL GOVERNANCE}

\section{ABSTRACT}

This paper seeks to assess the biofuels industry in Brazil under the viewpoint of institutional changes, their impact on governance model and systemic competitiveness. Based on the historical process of the ethanol sector were used concepts of systemic competitiveness, institutional change, punctuated equilibrium, advocacy coalition framework (ACF) and network governance to analyze the current institutional arrangement within the Federal Public Administration. From interviews with members of the Interministery Council for Sugar and Ethanol and Biodiesel Interministery Executive Committee, comprising the federal system of governance, we can see that even being an important component of the energy matrix, the biofuels industry still does not have a defined strategy broadly, showing a lack of coordination and weakness in governance mechanisms at the federal level. In the ethanol industry especially is noted that the Interministery Council of Sugar and ethanol presents difficulty in establishing the strategy clearly and mainly communicates it to the other members of the Federal Public Administration. The other bioenergy such as biogas or biomass are not treated within these governance bodies in a systemic way and disjointed isolated actions have been implemented by bodies of the Federal Public Administration.

KEYWORDS: Institutional Change; Governance; Biofuels.

\section{Revista Ibero-Americana de}

Ciências Ambientais, Aquidabã, v.4, n.1, Dez 2012, Jan, Fev, Mar, Abr, Mai 2013.

\section{ISSN 2179-6858}

\section{SECTION: Articles}

TOPIC: Políticas Públicas

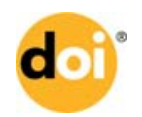

DOI: 10.6008/ESS2179-6858.2013.001.0006

Luciano Cunha de Sousa

Universidade de Brasilia, Brasil

http://lattes.cnpq.br/2445877007693602

luciano.cunha.sousa@gmail.com

Eliezé Bulhões de Carvalho

Universidade de Brasília, Brasil

http://lattes.cnpq.br/0752638062013650

elieze_carvalho@yahoo.com.br

Received: 04/10/2012

Approved: 01/04/2013

Reviewed anonymously in the process of blind peer.

\section{Referencing this:}

SOUSA, L. C.; CARVALHO, E. B.. Biocombustiveis no Brasil: mudanças institucionais, competitividade e governança federal. Revista Ibero-Americana de Ciências Ambientais, Aquidabã, v.4, n.1, p.69-87, 2013. DOI: http://dx.doi.org/10.6008/ESS2179$\underline{6858.2013 .001 .0006}$ 


\section{INTRODUÇÃO}

O setor de biocombustíveis é tido como um exemplo de sucesso brasileiro. Porém, a produção de etanol no Brasil mantém-se oscilando em torno de 27 bilhões de litros desde a safra 2008/2009, apesar da demanda potencial para o setor ser crescente ano à ano, devido à venda massiva de veículos flex. Já o biodiesel apresenta uma produção crescente, mas apesar de ter $52 \%$ de ociosidade da capacidade instalada BRASIL (2012a) não exportamos. Por que tal cenário se apresenta?

A competitividade sistêmica Esser et al. (1996) e Altenburg et al. (1998) considera que os fatores que estimulam ou dificultam o desenvolvimento industrial dinâmico não são somente os da empresa num nível micro ou da política econômica nacional num nível macro. Existem dois outros níveis de importância fundamental: no nível meta é tratada a capacidade de integração social e de formular e implementar estratégias; e no nível meso constam as estruturas de apoio, as políticas setoriais específicas que incentivam, complementam e aumentam os esforços no nível da empresa.

Sendo assim, a capacidade da Administração Pública Federal (APF) em se organizar, formular e implementar estratégias é considerada fundamental para a competitividade sistêmica. $A$ partir de entrevistas semiestruturadas com representantes dos principais Ministérios envolvidos com o tema, buscou-se compreender como a APF se organiza para tratar dos diversos aspectos relacionados aos biocombustíveis, bem como identificar alguns pontos falhos. Foi utilizado o marco teórico de gestão em rede na análise. Com a finalidade de compreender os acontecimentos que levaram ao modelo atual, realizou-se um breve levantamento histórico do setor de etanol, relacionando as mudanças com o referencial teórico de mudança institucional, equilíbrio pontuado e Advocacy Coalition Framework (ACF).

Numa avaliação econômica clássica, os biocombustíveis seriam produtos substitutos dos combustíveis fósseis. Ou seja, simplificando o conceito, poderíamos afirmar que o etanol concorreria com a gasolina e seria preferido pelo consumidor quando apresentasse custos inferiores. Sendo similar o caso do biodiesel em sua concorrência com o diesel. Porém, aqui não tratamos exclusivamente de uma curva de oferta e demanda clássica. Os biocombustíveis têm sido crescentemente utilizados no mundo por uma série de fatores: diminuição da emissão de gases de efeito estufa, melhoria da segurança energética, possibilidade de geração de renda de forma distribuída etc, que são motivações para o que Keohane e Victor (2011) chamam de complexo de regimes para mudança do clima. Sendo assim, além da Competitividade Sistêmica, que destaca a importância do governo para competitividade, neste setor específico, o governo tem um papel ainda mais amplo de avaliar as externalidades positivas destes outros fatores e decidir sobre a conveniência de se investir nesta área.

A existência de políticas públicas é essencial para o setor de biocombustíveis. De maneira geral os biocombustíveis têm um preço superior ao dos combustíveis fósseis. Existem algumas 
exceções como o caso do etanol no Brasil, que apresenta um preço vantajoso para o consumidor em alguns estados e em alguns períodos do ano. Porém, essa não é a regra, de forma que essa indústria tem sido criada por mandados legais instituídos das maneiras mais diversas. Mesmo no Brasil, este custo competitivo só foi obtido após décadas de investimento. Alguns países subsidiam a indústria, outros obrigam a mistura e repassam o custo para o consumidor, outros países aumentam artificialmente o preço dos combustíveis fósseis por intermédio de políticas tarifárias. O Brasil é um exemplo de país que usa diversas táticas para fomentar este segmento.

\section{REVISÃO TEÓRICA}

\section{O Setor de Biocombustíveis no País: Etanol}

O mercado de etanol no Brasil pode ser dividido em dois: o mercado do etanol hidratado e o de anidro, que tem uma mistura compulsória à gasolina, entre 18 e $25 \%$ estabelecida pela Lei $n^{\circ}$ 12.490 (BRASIL, 2011). Desde 01/10/2011 está se praticando a mistura de $20 \%$, conforme determinado pela Portaria MAPA nº 678 (BRASIL, 2011b).

Já o mercado de etanol hidratado era inicialmente para abastecimento dos veículos à etanol e atualmente abastece a frota de carros flex-fuel. Esta nova tecnologia, implantada no Brasil desde 2003 possibilita que o usuário escolha entre o etanol e a gasolina ao abastecer seu veículo. Apesar de cada motor possuir uma característica ótima para o etanol ou gasolina, foi estabelecido que em média é vantajoso abastecer o veículo com o etanol, quando o preço deste for $70 \%$ do preço da gasolina. Ou seja, neste caso o preço praticado para o consumidor final é determinante. Brasil (2011c) ao comparar o crescimento do consumo de combustíveis e do PIB nos mostra que desde 2007 há uma redução percentual do consumo de etanol hidratado. Ressalva-se que a frota de veículos flex-fuel cresce constantemente. De acordo com Associação Nacional dos Fabricantes de Veículos Automotores (ANFAVEA, 2012) o licenciamento de veículos leves flex-fuel representaram $86 \%$ do total em abril de 2012 e o setor alcançou a marca de 16,25 milhões de veículos flex-fuel licenciados desde 2003 com uma participação estimada na frota total de veículos leves de $49 \%$.

Em 2011 o Brasil importou 473 mil toneladas de etanol. As exportações tem se reduzido substancialmente (Figura 2) e parte significativa da exportação atual deve-se a contratos firmados anteriormente (QUEIROZ, 2011).

São vários os motivos para os problemas de produção de etanol, problemas climáticos nos anos recentes, rápida mecanização da colheita na região Centro-Sul, com impactos negativos na produtividade, alto grau de endividamento do setor na crise de 2008 etc. Mas um dos motivos relevantes para redução de investimentos no setor é a falta de margem para venda de preços do etanol hidratado. Os produtores alegam que os custos de produção subiram, mas que o preço de venda fica limitado aos $70 \%$ do valor da gasolina, que se encontra com o preço mantido artificialmente estável. Milanez et al. (2012) confirma que o etanol hidratado não tem obtido 
rentabilidade e que mantidas estáveis as condições atuais, teríamos um déficit de produção de etanol de 12 bilhões de litros em 2015.

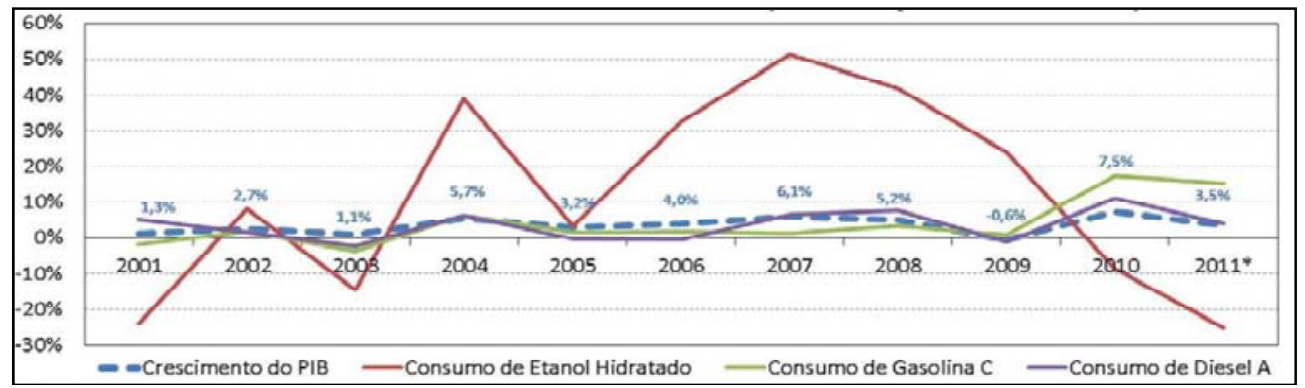

Figura 1: Crescimento do Consumo de Combustíveis e do PIB (\% em relação ao ano anterior). Fonte: Brasil (2011c).

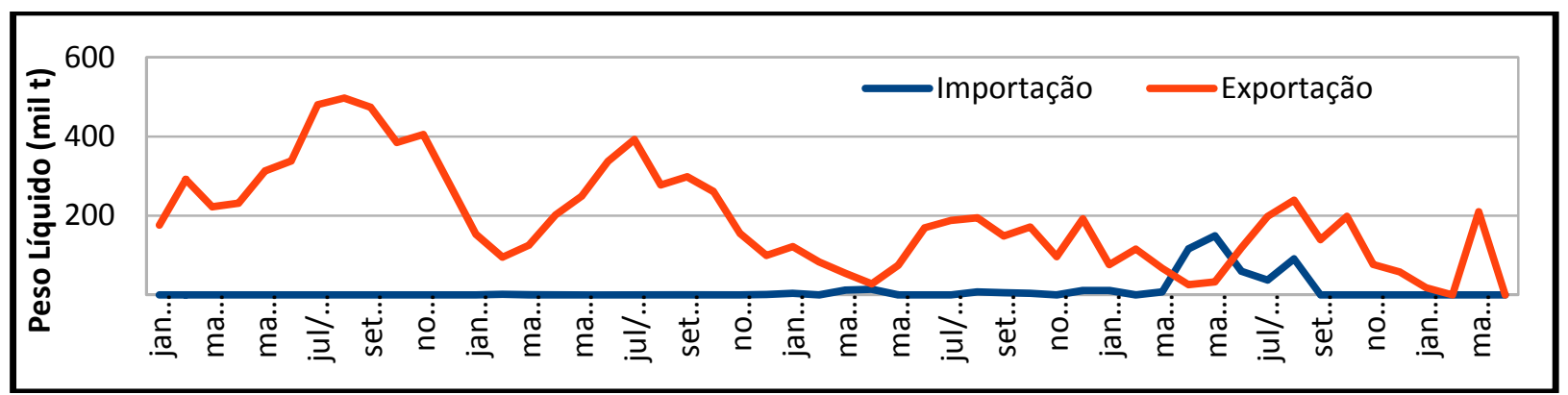

Figura 2: Comércio exterior de etanol - Exportação x Importação. Fonte: Brasil (2012). Elaboração Própria

\section{O Setor de Biocombustíveis no País: Biodiesel}

Após uma criteriosa análise da viabilidade ambiental, econômica e social da produção e uso do biodiesel em motores veiculares e estacionários, que concluiu e indicou a existência de externalidades positivas na geração de emprego e renda no campo, na produção das matérias primas oleaginosas e na redução das emissões com a combustão de biodiesel, foi estabelecido um marco regulatório objetivando a introdução sustentável e gradual do biodiesel na matriz energética brasileira. Este marco regulatório está constituído pela Lei n. 11.097/05, Brasil (2005), que introduz o biodiesel na matriz energética brasileira de forma gradual, com misturas autorizativa e obrigatória crescente de $2 \%$ a $5 \%$ de biodiesel ao diesel mineral em todo o território nacional; pela Lei n. 11.116/05, Brasil (2005a), que estabelece os incentivos fiscais à produção sustentável do biodiesel e variável de acordo com o tipo de produtor, matéria prima e região de produção; por decretos e demais atos normativos que regulamentam os benefícios fiscais e creditícios, o Selo Combustível Social, a produção, comercialização, especificação, qualidade e os leilões de compra do biodiesel.

O biodiesel teve o cronograma de misturas obrigatórias antecipadas, 2\% (B2) em 01/01/2008, 3\% (B3) em 01/07/2008, 4\% (B4) em 01/07/2009 e 5\% (B5) em 01/01/2010. Valor que só era previsto ser atingido em 2013. Na figura 3 pode-se observar a rápida expansão do setor.

Apesar do forte crescimento da produção estimulado pelas misturas compulsórias, o Brasil não consegue exportar biodiesel, enquanto a Argentina exportou 1,297 bilhões de toneladas em 2011 (BIOCOMBUSTIBLESHOY, 2012). 


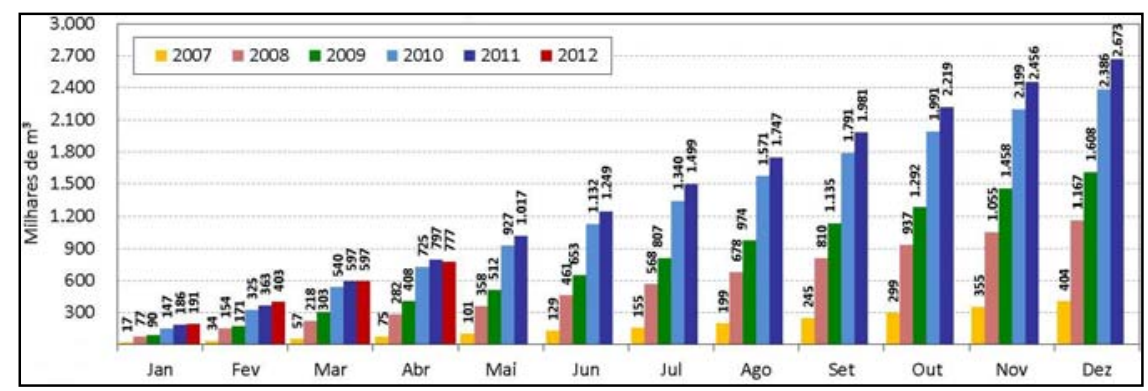

Figura 3: Produção de Biodiesel Acumulada. Fonte: Brasil, 2012a

\section{Competitividade}

Krugman (1997) situa o início das discussões mais amplas sobre competitividade das nações no início da década de 90, quando o presidente Clinton afirmou que cada nação é "como uma grande empresa no mercado global". E posteriormente, Jacques Delors declarou na Comunidade em Europeia, em junho de 1993, que o problema econômico dos europeus à época era causado por falta de competitividade. $O$ autor é um forte crítico do conceito de competitividade entre países, e afirma que "a taxa de crescimento do nível de vida é essencialmente igual à taxa de crescimento da produtividade". Para ele as nações não competem, somente as empresas. O principal argumento do autor é que as nações não podem sofrer a principal consequência da falta de competitividade que é o encerramento das atividades. Os países não saem do mercado, eles podem ter condições de vida piores, mas não desaparecerem.

Messner e Meyer-Stamer (1994) ao avaliarem as críticas do Krugman, destacam que "o Estado, obviamente, tem um papel importante no sucesso ou fracasso ao proporcionar um ambiente que acompanha a busca de competitividade das empresas" (p.73) e que este fenômeno é que traz à discussão o conceito de competitividade sistêmica.

Os autores ressaltam quatro fatores importantes que são pontuados pelo termo sistêmica: (1) Sem um conjunto de provedores de serviços e sem a pressão competitiva de concorrentes locais seria raro uma empresa ser competitiva; (2) As instituições gerais e específicas e o modo de organização de uma sociedade é que geram um ambiente propício para competitividade; (3) O Estado tem um papel importante no desenvolvimento e reestruturação industrial; e (4) Existem forte inter-relações entre os níveis meta, macro, meso e micro.

A teoria econômica clássica trabalha com a empresa num nível micro e a política econômica nacional num nível macro. Os autores que desenvolveram estudos sobre competitividade estrutural, como Chesnais (1990) incluíram o nível meso nas discussões sobre competitividade. Neste nível constam as estruturas de apoio, as políticas setoriais específicas que incentivam, complementam, e aumentam os esforços no nível da empresa. Já na competitividade sistêmica Altenburg et al. (1998) e Esser et al. (1996) incluem o nível meta, onde é tratada a capacidade de integração social e de formular e implementar estratégias.

Parece-nos que tem havido um crescente reconhecimento da complexidade ligada ao processo de geração de inovação e de competitividade, e tal fato nos leva a crer que a 
competitividade sistêmica de Esser et al.(1996) forneça uma abordagem adequada para analisar as políticas relacionadas ao setor.

Para Altenburg et al. (1998) a análise do nível meso da competitividade sistêmica consiste em duas partes. As mesoinstituições, que oferecem serviços específicos para as firmas industriais e as mesopolíticas, que trabalham a regulação e outras condições específicas de um setor. Neste estudo serão avaliadas as estruturas de governança para formulação das mesopolíticas.

\section{Etanol: História e mudança institucional}

Instituições são em geral retratadas como regras, normas e procedimentos que influem ou moldam o comportamento e que não podem ser mudadas de maneira fácil ou instantânea. Mahoney e Thelen (2010) consideram que a própria definição dificulta a compreensão das mudanças institucionais, suas causas e consequências. Nesta seção, por questão de simplificação, será apresentado um breve levantamento das alterações legais significativas para o setor de etanol, buscando associar estas mudanças com a teoria de mudança institucional, ACF e equilíbrio pontilhado.

Em 1516, o rei D. Manuel, de Portugal, promulga o primeiro alvará tratando de promover o plantio da cana-de-açúcar, principal matéria-prima para o etanol, determinando que se encontrasse gente prática capaz de dar princípio a um engenho de açúcar no Brasil (UDOP, 2007). Em 1903, nas conclusões do I Congresso Nacional sobre Aplicações Industriais do Álcool, já se recomendava o uso de álcool como combustível automotivo no Brasil (GOLDEMBERG et al. 1993). Em 1931, o Decreto n. 19.717 (BRASIL, 1931) impôs uma mistura compulsória de, no mínimo, $5 \%$ de álcool anidro à gasolina importada. A motivação alegada era a redução da dependência de importação de derivados de petróleo. Porém, neste mesmo período o país tinha uma superprodução da indústria açucareira, que levou à criação do Instituto do Açúcar e Álcool IAA, a partir do Decreto $n^{\circ} 22.789$ (BRASIL, 1933) com a responsabilidade de controlar o setor. Logo no início do uso do etanol no setor automotivo, observa-se que havia uma oportunidade gerada pela escassez de produção de petróleo e derivados no país, que foi bem apropriada pelo setor açucareiro, em consonância com a proposição da ACF de Sabatier e Weible (2007). Também pode se associar a decisão com um processo de lata de lixo (MARCH, 2009), considerando-se que a solução de mistura do etanol à gasolina já estava disponível desde 1903 e que foi adotada a partir de um problema de abastecimento/custo em 1933.

A Segunda Guerra Mundial impôs grande escassez na oferta mundial de derivados de petróleo, passando, em 1941, a ser obrigatória no Brasil a mistura de $20 \%$ de etanol na composição da gasolina. Como não houve um crescimento rápido da oferta de etanol, o IAA, que controlava cotas para a instalação de novas usinas de açúcar passou a condicionar a liberação destas à construção de destilarias anexas de etanol anidro. As usinas de São Paulo aproveitaramse do período para pedir a revisão geral das cotas, que ocorreu por meio do Decreto-Lei $n^{\circ} 9.827$ 
(BRASIL, 1946). Esse período dá início ao aumento da produção no estado, em detrimento do Nordeste que era a região de maior produção até aquele período. Tal fato é associado com a proposição de Streeck e Thelen (2005) sobre a divergência entre atores como fonte de mudança institucional.

A urbanização e industrialização crescentes na década de 50 foram fortes indutores para indústria de etanol na região Centro-Sul, já que era esta a região que mais se desenvolvia no país. O IAA também passou a praticar políticas de preços, que beneficiavam o deslocamento da agroindústria canavieira da Região Nordeste para o estado de São Paulo. Desde o início do etanol como combustível veicular houveram variações nos percentuais de mistura à gasolina, que situaram-se em média, em $7,5 \%$ até 14 de novembro de 1975 , quando o primeiro choque do petróleo levou a criação do Decreto no 76.593 (BRASIL, 1975), que colocou oficialmente em funcionamento o PROÁLCOOL, cujas principais metas eram: fixar a proporção da mistura da gasolina em $20 \%$, ter a cana-de-açúcar como matéria-prima industrial, estimular a ampliação da lavoura canavieira, incentivar a instalação de destilarias anexas e autônomas, além de fomentar o desenvolvimento da produção de etanol advindo de fontes alternativas como, por exemplo, a mandioca. O decreto também formalizou a criação da Comissão Nacional do Álcool (CNA).

Já no início da década de 70, várias medidas vinham sendo tomadas para promover uma maior produção do etanol. Foi criado o Programa Nacional de Melhoramento da Cana-de-Açúcar PLANALSUCAR, em 1971, o Programa de Racionalização da Agroindústria Canavieira, no mesmo ano, e o Programa de Apoio à Indústria Açucareira, iniciado em 1973. Para Bertelli (2007) o planejamento foi formulado a partir do embate entre duas propostas. O IAA defendia a produção exclusiva do etanol em destilarias autônomas e a Copersucar, principal cooperativa de produtores de açúcar, defendia que as usinas fossem mistas e produzissem etanol e açúcar na mesma unidade, de maneira a aproveitar a capacidade ociosa das usinas açucareiras. A proposta da Copersucar foi vitoriosa. Como o setor alegava à época que os preços do açúcar e etanol fixados pelo IAA não cobriam os custos de produção, houve concessão de créditos e subsídios destinados aos produtores do setor.

Em 1979 houve novo choque do petróleo e intensificação do Proálcool, que passou a estimular o uso de etanol hidratado em motores adaptados ou especificamente produzidos para o emprego desse biocombustível. O Decreto n. 83.700 (BRASIL, 1979) criou Conselho Nacional do Álcool (CNAL), para condução geral do Proálcool, e a Comissão Executiva Nacional do Álcool (CENAL), responsável pela implementação do programa (CGEE, 2007) e que substituiria a CNA.

Com a redução do preço do petróleo e recuperação dos preços do açúcar, foram reduzidos os benefícios ao setor a partir de 1986. Em 1989 iniciaram-se problemas de oferta do produto, tendo sido necessário reduzir teor de etanol na gasolina, a importação de etanol e o uso de metanol como substituto ao etanol na mistura com a gasolina. Scandiffio (2005) destaca que após os veículos movidos à etanol terem chegado à $85 \%$ do total de veículos novos, em 1990 eram somente $11,4 \%$. Situação que se reverteu a partir de 2003 com o lançamento dos veículos flex. 
Na década de 90 houve um movimento de liberalização econômica intenso no país com fortes reflexos no setor. Iniciou-se a extinção dos subsídios e o fim do tabelamento dos preços do etanol, processo concluído em 1999. O IAA teve as suas atividades encerradas em 15 de março de 1990. Os benefícios tributários ao etanol hidratado e ao carro flex permanecem, bem como a obrigatoriedade dos postos de combustível no território nacional terem no mínimo uma bomba de abastecimento de etanol hidratado. É destacado por BNDES (2008) que este rearranjo econômico se deu num ambiente divergente com empresários conservadores que pretendiam manter 0 intervencionismo no setor e outros que preferiam um mercado mais aberto.

Conforme defendido por Streeck e Thelen (2005) e Mahoney e Thelen (2010), as mudanças institucionais são graduais e frequentemente ocorrem de maneira incremental. Pode-se observar que as mudanças na governança federal para os biocombustíveis tem seguido esta lógica incremental. A Agência Nacional do Petróleo (ANP) foi criada pela Lei n. 9.478 (BRASIL, 1997a), tendo sido renomeada pela Lei n. 11.097 (BRASIL, 2005) para Agência Nacional do Petróleo, Gás Natural e Biocombustíveis. Porém, somente com a edição da Medida Provisória n. 532/2011 (BRASIL, 2011), convertida na Lei n. 12.490/2011 (BRASIL, 2011a) a Agência passou a controlar efetivamente o setor de etanol. No âmbito político, o Decreto de 27 de outubro de 1993 (BRASIL, 1993), instituiu, sob controle do Ministério de Minas e Energia a Comissão Interministerial do Álcool - CINAL; transferida para o Ministério da Indústria, do Comércio e do Turismo (MICT) pelo Decreto de 12 de setembro de 1995 (BRASIL, 1995). Já o Decreto n. 5.652 (BRASIL, 1997) cria o Conselho Interministerial do Açúcar e do Álcool - CIMA, sob a presidência do MICT, que teve sua composição alterada e foi transferido para presidência do MAPA pelo Decreto n. 3.546 (BRASIL, 2000a). As mudanças de presidência/coordenação do Conselho Interministerial do Açúcar e do Álcool refletem que as mudanças são em parte reflexo do balanço de poder alterado conforme preconizado por Thelen (1999).

Ao observar a figura 4 sobre o teor médio de etanol anidro na gasolina brasileira, poderíamos considerar que a proposição da Teoria do Equilíbrio Pontuado de True et al. (2007) representa adequadamente as mudanças do setor de etanol. Porém, ao analisar o histórico do setor, em suas nuances, brevemente relatadas acima, verifica-se que as mudanças não são repentinas como poderia ser depreendido do gráfico, mas sim geradas por vários pequenos ajustes que se acumulam e geram mudanças significativas (MAHONEY; THELEN, 2010). Mas, ao mesmo tempo, verifica-se, conforme proposto por True et al. (2007) que várias das mudanças ocorridas são advindas de choques exógenos, como as crises do petróleo.

Streeck e Thelen (2005) enfatizam que as instituições sociais são "continuamente criadas e recriadas por um grande número de atores, com interesses divergentes, compromissos normativos variáveis [e] poderes diferentes". As diversas criações, modificações e recriações de Conselhos relacionados ao etanol, bem como as recentes e relativamente rápidas mudanças no nome e atribuições da ANP comprovam tal consideração e reforçam o argumento da mudança institucional gradual e frequente. 


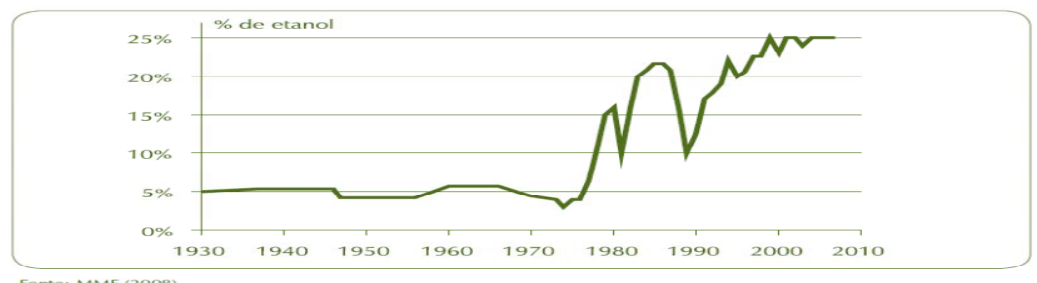

Figura 4: Teor médio de etanol anidro na gasolina brasileira

Quanto aos modos e agentes da mudança institucional, utilizando a nomenclatura proposta por Mahoney e Thelen (2010), considerou-se que as diversas mudanças legais para o setor de etanol, em geral enquadram-se como substituição (displacement) e por camadas (layering). Em alguns momentos as regras antigas foram substituídas, mas em grade parte do tempo houveram adições de regras às já existentes. Brasil (2009) ao relacionar a legislação do setor entre 1931 e abril de 2009, lista 71 leis, 116 medidas provisórias, 240 decretos, 291 resoluções, 289 portarias, 11 instruções normativas e 236 atos regulamentando o setor no período, confirmando a existências de mudanças constantes e incrementais no setor. Sendo um setor fortemente regulado, os usineiros, como agentes de mudança institucional foram identificados como simbiontes mutualistas, já que eles necessitam das regras que criam e mantém o setor e obtém ganhos privados a partir destas.

\section{Governo em Rede}

Weaver e Rockman (1993 citado por LABRA, 1999) relacionam dez capacidades que são necessárias a todos os governos: definir e sustentar prioridades; destinar recursos para os objetivos mais eficazes; inovar quando as velhas políticas fracassam; coordenar metas conflitantes; impor perdas a grupos poderosos; representar interesses difusos e desorganizados ao lado dos interesses mais concentrados e bem organizados; garantir a execução dos programas; assegurar a estabilidade dessas políticas, para que possam produzir efeitos; estabelecer e manter compromissos internacionais, visando o bom desenvolvimento a longo prazo; e sobretudo, administrar as clivagens políticas, para que não ocorra uma guerra civil.

$\mathrm{Na}$ década de 70 vários países tentaram reestruturar suas sociedades de uma maneira top-down usando um modelo hierárquico de governança. Sem estender-se acerca dos motivos, verifica-se que esse modelo não foi bem sucedido, gerando severas estagnações na década de 80, como foi o caso no Brasil. Mayntz (1991) considera que modelos de governança autocráticos e hierárquicos estão se tornando obsoletos e que novas formas de governança estão emergindo baseadas numa nova maneira de interação entre o estado e atores sociais, tipicamente em redes horizontais.

Para Jordan e Schubert (1992 citado por LABRA, 1999) dada a nova realidade política do processo público - transformado por fatores como a organização da sociedade em coletividades; a setorialização, sobrecarga e ampliação do policy-making; a fragmentação do Estado e o 
embaçamento das fronteiras entre o público e o privado - várias "metáforas" têm sido utilizadas para descrever os formatos de intermediação de interesses: comunidades políticas, redes políticas ou redes de questões. Labra (1999) ao concluir sua análise sobre políticas, modos de policymaking e intermediação de interesses afirma que "o modelo de policy-making tende a configurarse em clusters de redes de política ou de comunidades de política cada vez mais especializadas, restritas e com tendências oligárquicas, nas quais predominam representantes da burocracia estatal qualificados legal e politicamente para tanto".

Para melhorar a coordenação entre os distintos níveis institucionais a forma políticainstitucional que parece mais adequada é o estado em rede (CASTELLS, 1998). Marini e Martins (2004) propõem o governo matricial como uma maneira de tratar dois problemas: a baixa implementação dos planos estratégicos formulados e a fragmentação, considerada como falhas de coerência, coordenação e consistência nas políticas e programas de governo. Para os autores "trata-se de se sobrepor à estrutura governamental (predominantemente) mecanicista, estruturas em rede com feições orgânicas voltadas para resultados." O novo Estado-rede passa então a ser um elemento concertador, ativador e direcionador do mercado e sociedade civil. Que, para Castells (1998) "se caracteriza pelo compartilhamento da autoridade (a capacidade institucional de impor uma decisão) no âmbito de uma rede de instituições."

Para Agranoff e McGuire (2001 citado por MARINI; MARTINS, 2004) o governo em rede são "arranjos multi-organizacionais para resolver problemas que não podem ser abordados, ou abordados facilmente através de uma única organização". Esta organização não substitui as estruturas hierárquicas, mas atendem bem as situações híbridas que apresentam crescente complexidade dos ambientes interno e externo (MORGAN, 1997).

Para Messner e Meyer-Stamer (1994) a interação entre o Estado e os atores sociais, está mudando, iniciando-se uma organização segundo redes horizontais. Para os autores o papel do governo passa a ter o papel de coordenar e moderar as interações entre as empresas, associações, academia sindicatos etc, possibilitando o planejamento de médio e longo prazo, que possam servir de referência para as mesopolíticas de governo e da iniciativa privada.

Embora talvez não seja uma opção deliberada e explícita, observa-se que o Governo Brasileiro possui uma organização matricial, se não, em todos os temas, pelo menos em alguns. No setor de biocombustíveis, esta organização é observada na existência de Conselhos e Comissão que são integrados por vários órgãos. Na sequencia será analisado um pouco mais detalhadamente a organização formal destes grupos no âmbito da APF.

\section{A Estrutura Legal de Governança dos Biocombustíveis na APF}

Os Princípios da Política Energética Nacional brasileira são estabelecidos pela Lei $n^{\circ} 9.478$ (BRASIL, 1997a). Nesta lei já constava a obrigatoriedade de se incentivar as energias renováveis, as quais incluíam os biocombustíveis. A Medida Provisória n. 532, Brasil (2011), fez uma série de 
alterações no texto original, explicitando e reforçando o papel dos biocombustíveis. Os Princípios podem ser resumidos como: (A) Proteger os interesses do consumidor quanto a preço, qualidade e oferta dos produtos; (B) Proteger o meio ambiente e promover a conservação de energia; (C) Garantir o fornecimento; (D) Utilizar fontes alternativas de energia; (E) Promover a livre concorrência; (F) Ampliar a competitividade do País no mercado internacional.

\section{CNPE: Conselho Nacional de Política Energética}

O Conselho Nacional de Política Energética (CNPE) é um órgão de assessoramento do Presidente da República. Sua função é formular políticas e diretrizes de energia de acordo com os princípios legais estabelecidos. O CNPE teve a sua composição estabelecida pelo Decreto $\mathrm{n}$. 3.520 (BRASIL, 2000), com inclusões realizadas pelos Decretos n. 5.793 (BRASIL, 2006) e n. 6.685 (BRASIL, 2008). Sendo integrantes atuais do Conselho: os Ministros de Estado de Minas e Energia; da Ciência e Tecnologia; do Planejamento, Orçamento e Gestão; da Fazenda; do Meio Ambiente; do Desenvolvimento, Indústria e Comércio Exterior; da Integração Nacional; da Agricultura, Pecuária e Abastecimento; o Ministro Chefe da Casa Civil da Presidência da República; um representante dos Estados e do Distrito Federal; um representante da sociedade civil especialista em matéria de energia; um representante de universidade brasileira, especialista em matéria de energia; o Presidente da Empresa de Pesquisa Energética - EPE; e o SecretárioExecutivo do Ministério de Minas e Energia.

\section{CIMA: Conselho Interministerial do Açúcar e do Álcool}

O Conselho Interministerial do Açúcar e do Álcool (CIMA) é atualmente regido pelo Decreto n. 3.546 (BRASIL, 2000a), sendo composto pelos Ministérios: da Agricultura e do Abastecimento; da Fazenda; do Desenvolvimento, Indústria e Comércio Exterior; e de Minas e Energia. O objetivo do CIMA é deliberar sobre as políticas relacionadas com as atividades do setor sucroalcooleiro, considerando, entre outros, os seguintes aspectos: (1) adequada participação dos produtos da cana-de-açúcar na Matriz Energética Nacional; (2) mecanismos econômicos necessários à autosustentação setorial; (3) desenvolvimento científico e tecnológico.

\section{CEIB: Comissão Executiva Interministerial do Biodiesel}

Compete à Comissão Executiva Interministerial (CEIB) elaborar, implementar e monitorar programa de biodiesel, propor os atos normativos que se fizerem necessários à implantação do programa, assim como analisar, avaliar e propor outras recomendações e ações, diretrizes e políticas públicas (BRASIL, 2011d).

A Comissão Executiva Interministerial subordina-se à Casa Civil da Presidência da República e é integrada por um representante dos seguintes órgãos: Casa Civil da Presidência da 
República; Secretaria de Comunicação de Governo e Gestão Estratégica da Presidência da República; Ministérios da Fazenda; dos Transportes; da Agricultura, Pecuária e Abastecimento; do Trabalho e Emprego; do Desenvolvimento, Indústria e Comércio Exterior; de Minas e Energia; do Planejamento, Orçamento e Gestão; da Ciência e Tecnologia; do Meio Ambiente; do Desenvolvimento Agrário; da Integração Nacional; das Cidades; e do Desenvolvimento Social.

Ao analisar os Conselhos e a Comissão observa-se a grande variedade de instituições que participam de cada um deles, criando arranjos institucionais distintos e coincidentes entre os três. Dessa forma, as políticas públicas do setor estão inseridas em uma estrutura específica combinando o setor público e privado, como também a sociedade civil em geral. A esse arranjo, que pode-se considerar uma rede de políticas publicas que é de acordo com Calmon (2010) um conjunto dos relacionamentos entre atores heterogêneos e interdependentes, que estejam atuando em um mesmo subsistema de políticas públicas a partir de determinada estrutura de governança, composta por regras formais, informais e maneiras e formas de interpretá-las e implementá-las

Além disso, para Schneider (2005), o conceito de redes inclui interação de muitos atores distintos; o envolvimento na formulação e implementação de políticas públicas por vários atores (públicos e privados); existência de vínculos diretos e indiretos relativamente duradouros; diferença de poder entre os múltiplos atores; e posições de poder e influência que transcendem o status político-institucional.

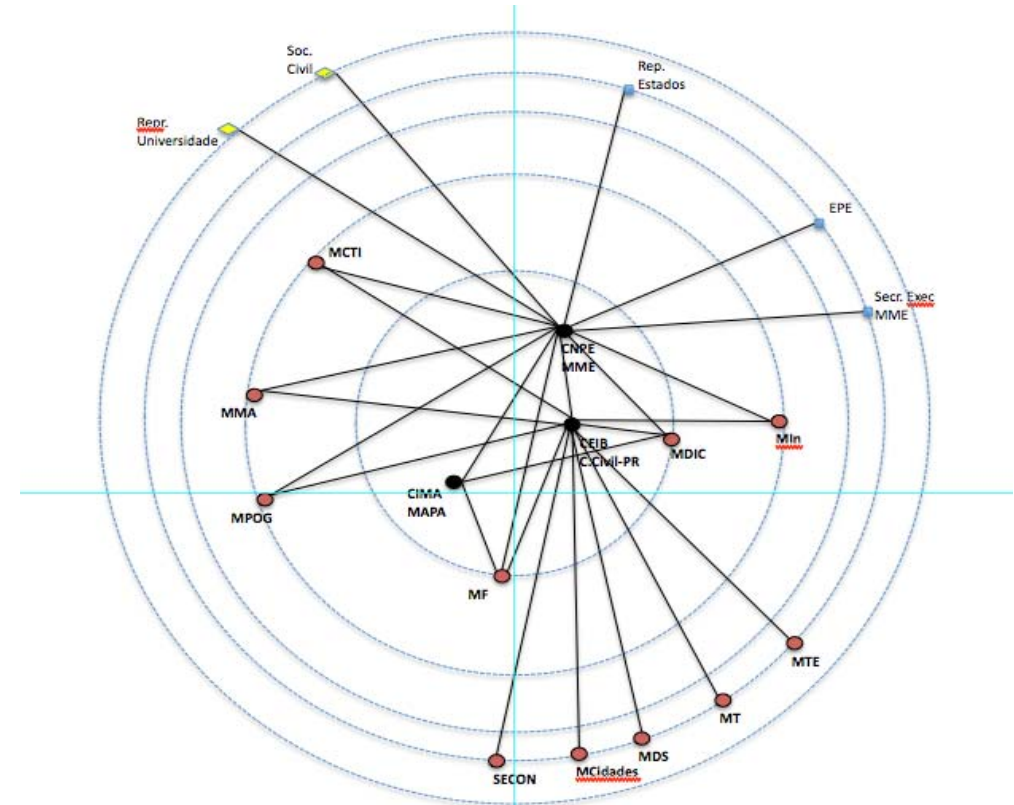

Figura 5: Redes de relacionamento entre os integrantes do CNPE, CEIB e CIMA.

A figura 5 a seguir ilustra as redes originadas pelas relações entre o CNPE, CIMA, CEIB ao centro e os seus membros participantes. A metodologia para sua criação seguiu a proposta de laços entre os atores. Quanto mais laços existem entre os diferentes agentes integrantes do Conselho ou das Comissões, mais próximo eles estarão do centro. 


\section{METODOLOGIA}

Foram realizadas entrevistas semiestruturadas com representantes dos principais Ministérios envolvidos com a política de biocombustíveis: Desenvolvimento, Indústria e Comércio Exterior; Desenvolvimento Agrário; Agricultura, Pecuária e Abastecimento; Ciência, Tecnologia e Inovação; Minas e Energia e Casa Civil.

Optou-se por realizar as entrevistas sem gravação e identificação dos participantes pois se desejava obter as opiniões das pessoas participantes do processo e conhecedoras do assunto. Em contatos preliminares foi constatado que com a existência de gravação os entrevistados necessitariam fornecer as "posições oficiais" sobre as questões apresentadas já que eram representantes de seus respectivos órgãos nos conselhos e comissão referidos.

Segundo Flick (2009) a entrevista semi-estruturada parte de questionamentos básicos, apoiados em hipóteses e teorias e ao desenrolar oferece campo a novas interrogativas à medida que o entrevistado vai discorrendo sobre o tema.

\section{RESULTADOS}

Marini e Martins (2004) destacam que para o Governo Matricial gerar resultados adequados, é necessário alinhamento horizontal e vertical. O alinhamento horizontal contempla o alinhamento dos pontos de implementação no âmbito de cada programa, com a definição de arranjos específicos de coordenação para que os resultados dos respectivos programas possam ser alcançados. O alinhamento vertical requer o alinhamento das organizações com os resultados dos programas que as perpassam. Será que o arranjo institucional brasileiro tem garantido o alinhamento horizontal e vertical necessários ao sucesso dos programas de biocombustíveis?

Todos os entrevistados afirmaram que não recebem orientações ou determinações do CNPE para execução de suas atividades. Alguns comentaram que no caso do biodiesel, o CNPE foi envolvido somente para homologar os aumentos de mistura do biodiesel ao diesel, conforme exigido pela Lei n. 11.097 (BRASIL, 2005). Um dos entrevistados, inclusive, informou que as decisões do CNPE relativas aos aumentos de mistura de biodiesel que ocorreram: $3 \%$ em 01/07/2008, 4\% em 01/07/2009 e 5\% em 01/01/2010, foram todas decididas pelo presidente do CNPE e homologadas ad referendum e que somente posteriormente o assunto foi levado à reunião do Conselho. Tais decisões foram discutidas no âmbito da CEIB, feita uma exposição de motivos para justificar a proposição de aumento da mistura e enviado ao CNPE devido às exigências legais.

Alguns dos comentários sobre o CNPE foi que ele é um Conselho "elétrico" e que biocombustíveis é um assunto muito pequeno para o Conselho, que envolve um grande número de Ministros. 
Pode-se concluir que o CNPE não tem se envolvido no planejamento ou na condução de ações relacionadas aos biocombustíveis, apesar de ter esta atribuição legal. Cabe ressaltar que a recente mudança governamental na área de biocombustíveis, passando o controle do setor de etanol do MAPA para o MME/ANP alterou as atribuições do CNPE, explicitando e reforçando o papel desse Conselho neste segmento. As atas de reunião do CNPE desde 23/06/2009 foram avaliadas e neste período houveram duas reuniões, em 23/06/2009 e 08/12/2009 nas quais foram homologados os aumentos de mistura de biodiesel ao diesel. Nas demais reuniões o tema não foi tratado. Destaca-se ainda que no mandato atual da presidente Dilma, somente foi realizada uma reunião do conselho, em 28/04/2011.

Quanto à atuação do CIMA, houve entrevistado que apesar de ter importante atuação no setor de etanol simplesmente desconhecia este Conselho. Outros entrevistados que não são de Ministérios que participam do CIMA, ou que não são os representantes de seus órgãos no Conselho afirmaram não conhecer a atuação do órgão, a não ser as reuniões que determinaram aumentos ou diminuições da mistura de etanol à gasolina.

Dentre os entrevistados que participam do CIMA, há um consenso que este Conselho foi perdendo a "força" e que atualmente quase somente se reúne para decidir sobre o percentual de mistura do etanol à gasolina. De fato, em boa parte das vezes as reuniões nem mesmo ocorrem, a decisão é proposta ad referendum. Um dos entrevistados apresentou uma justificativa para tal fato. Segundo o mesmo, no governo do presidente Lula o setor de etanol tinha uma grande força política e tinha um trânsito muito fácil diretamente com a Presidência da República. Tal situação diminuiu o poder do CIMA, pois quando representantes do setor necessitavam de discutir ou resolver alguma coisa iam diretamente ao Ministério responsável e faziam a requisição. Como era conhecida a predileção do presidente pelo tema e os estreitos laços com o setor, a maioria dos pleitos era atendida. Com essa interação direta com cada instituição o papel do Conselho foi sendo reduzido.

Os entrevistados que não são representantes de seus órgãos no CIMA foram unânimes em afirmar que não recebem orientações ou diretrizes deste Conselho. Instituições com atuação importante no setor usam de mecanismos diversos para estabelecer suas prioridades de ação, já que não há uma comunicação formal ou informal sobre quais devem ser as prioridades a cada período. Outro consenso dos entrevistados é que falta ao CIMA a representação de alguns Ministérios que são relevantes para o tema. Quanto à quais seriam os Ministérios a serem incluídos, não houve concordância.

Dentre os órgãos oficialmente constituídos para governança do setor de biocombustíveis, a CEIB foi aquele que se destacou como sendo considerado o que tem uma atuação melhor. De maneira geral os entrevistados concordam que o espaço de discussão instituído na Comissão é proveitoso, permitindo aos participantes conhecer os vários aspectos do Programa de Biodiesel, bem como seus problemas. Também há concordância que neste caso as diretrizes são mais claramente definidas. Um dos entrevistados afirmou que mesmo não recebendo periódica e 
formalmente as diretrizes que deveria seguir, consegue nas reuniões antever problemas e já buscar tratá-los.

Questionados sobre a diferença de atuação do CIMA e da CEIB, é consenso dos entrevistados que a maturidade dos setores de etanol e do biodiesel é bastante diferente e que tal fato se reflete no Conselho e na Comissão. Numa fase considerada de implantação, o biodiesel necessitaria de uma supervisão mais estreita e devido a suas características de envolvimento do aspecto social necessita de mais instituições envolvidas. O atual momento é de avaliação das atividades para se definirem os princípios e diretrizes futuras.

Um dos entrevistados considerou extremamente adequada a atuação da CEIB, que redigiu um relatório dos resultados e principais problemas ocorridos e que realizou um ciclo de audiências públicas no início de 2011 para discutir com todos os envolvidos o futuro do Programa de Produção de Biodiesel. Não identificamos que algo similar tenha sido feito para o setor de etanol, no âmbito do CIMA.

Também houve consenso entre os participantes sobre a inadequação da composição atual da CEIB. Se no etanol a questão é acrescentar algumas instituições importantes, no biodiesel a questão é inversa, existem participantes em excesso. Diversos entrevistados informaram que vários Ministérios que são formalmente participantes da CEIB não participam das reuniões ou são pouco relevantes para as atividades a serem executadas. Tal fato foi considerado como derivado da preocupação inicial de incluir todos os possíveis envolvidos com as questões do Biodiesel. Atualmente, os entrevistados consideram que já é sabido quais são os órgãos mais envolvidos com o tema e que uma redução na composição da Comissão seria proveitosa para dar mais agilidade às discussões.

Um tópico que não havia sido previamente planejado para ser abordado nas entrevistas foi o relacionamento dos Ministérios com suas "agências", aí se considerando as instituições da Administração Indireta, Institutos e órgãos de fomento. Alguns entrevistados afirmaram que um dos fatores responsáveis por certa descoordenação governamental é a independência das agências. Dois entrevistados citaram o caso do Inmetro, que iniciou o desenvolvimento de um programa de certificação de biocombustíveis que foi considerado inadequado pelos diversos Ministérios envolvidos com o tema. O programa só foi interrompido após severas desavenças entre alguns líderes das instituições envolvidas na discussão e intervenção do $1^{\circ}$ escalão do governo. Teve entrevistado que considerou que tal situação só será resolvida com a inclusão das agências diretamente nas discussões e nos fóruns decisores. Outro entrevistado considera que tal problema tem diminuído e que tem ocorrido uma melhor definição sobre o papel dos Ministérios e suas agências vinculadas, permitindo uma melhor coordenação.

Messner e Meyer-Stamer (1994) ao tratarem sobre a inconveniência do planejamento hierárquico convencional, destacam que "o requisito de know-how para formular políticas de longo prazo e as capacidades de implementação se distribuem por uma variedade de agências 
governamentais, privadas e intermediárias." Concordando com um dos entrevistados que considera que as agências governamentais devem participar mais ativamente das discussões.

\section{CONCLUSÕES}

Ferraz et al. (1997), Tyson (1992) e Bianco (2007) indicam as exportações como um indicador de desempenho competitivo. Sob este aspecto podemos afirmar que o setor de biodiesel brasileiro não apresenta competitividade sistêmica. Já o setor de etanol, apesar de exportar, não consegue produzir o suficiente, a um preço competitivo, para atender a demanda interna e externa. São vários os fatores que influem em tal situação, tais como, câmbio, problemas climáticos, mercado internacional do açúcar, preço do petróleo etc. No presente texto nos fixamos na governança da Administração Pública Federal, com algumas conclusões apresentadas a seguir.

O Brasil não possui uma estratégia definida para os biocombustíveis de forma ampla. Não existem metas claras quantificadas, e consequentemente também não existem definições sobre quais os caminhos a seguir. Existem determinações legais para misturas de etanol à gasolina e de biodiesel ao diesel. Porém, no setor de etanol não foram identificadas medidas coordenadas para se garantir o abastecimento necessário para mistura obrigatória. Quanto ao consumo livre de etanol hidratado, diretamente nos carros a etanol ou flex, também não identificamos medidas para garantia do abastecimento.

Cabe ressaltar que houve uma profunda desregulamentação do setor de etanol na década de 90, deixando o mercado quase totalmente livre. Com a crise de oferta que vem ocorrendo, já houve uma reação governamental com as alterações propostas pela MP 532. Não é possível ainda avaliar os efeitos de tais alterações.

No setor de biodiesel a fase inicial de implantação prevista para atingir os $5 \%$ de mistura já se concluiu e a CEIB elaborou uma proposta de Projeto de Lei que está em análise pela equipe da casa Civil.

Não foi identificada nenhuma estrutura articulada no governo que esteja discutindo as outras alternativas de energia derivadas da biomassa, tais como o bioquerosene de aviação ou o biogás. Tais discussões ocorrem, porém, em âmbitos de uma ou outra instituição interessada no tema, sem um mecanismo de coordenação.

Os Conselhos formados por Ministros praticamente não se reúnem e quando o fazem é somente para referendar propostas já previamente discutidas ou para debater tópicos muito específicos sobre os quais não há consenso entre os técnicos. Estes Conselhos não tem sido úteis para formular diretrizes para o setor. Dentre os órgãos formais relacionadas à governança dos biocombustíveis na APF, somente a CEIB foi identificada como formuladora de diretrizes e como uma instituição de acompanhamento efetivo das atividades dos diversos envolvidos. 
Para atingir a competitividade sistêmica (ESSER et al., 1996; Altenburg; Hillebrand; MeyerStamer, 1998) a capacidade de integração social e de formular e implementar estratégias é fundamental, sendo denominada de nível meta. Na pesquisa e nas entrevistas realizadas, observamos que os mecanismos de governança da APF para o setor não contemplam a totalidade dos assuntos (só envolvem biodiesel e bioetanol) e não são efetivos em coordenar todas as atividades. Este nível necessita ser mais bem organizado e implementado.

O estado em rede (CASTELLS, 1998; MARINI; MARTINS, 2004) como um elemento concertador, ativador e direcionador do mercado e sociedade civil ainda não está funcionando adequadamente para os biocombustíveis. Necessitamos evoluir nossa capacidade matricial de trabalho para reforçar o nível meso de coordenação para formular e implementar estratégias.

\section{REFERÊNCIAS}

ALtenbuRg, T.; HILLEBRAND, W.; MEYER-STAMER, J.. Policies for Building Systemic Competitiveness. Conceptual Framework and Case Studies of Mexico, Brazil, Paraguay, Korea and Thailand. Berlin: German Development Institute, 1998.

ANFAVEA. Tabelas estatísticas. Disponível em : <http://www.anfavea.com.br/tabelas.html>. São Paulo. Acesso: 16 jul 2012.

BERTELLI, L. G.. A verdadeira história do Proálcool: Programa Nacional do Álcool. O Estado de São Paulo, São Paulo, 30 out 2007.

BIANCO, C.. ¿De qué hablamos cuando hablamosde competitividad?. Buenos Aires: Centro de Estudios Sobre Ciencia, Desarrollo Y Educación Superior (REDES), Documento de Trabajo n.31, marzo, 2007.

BIOCOMBUSTIBLESHOY. Boletín n. 60. Bogotá. Disponível em: <www.fedebiocombustibles.com>, 2012.

BNDES. Bioetanol de Cana-de-Açúcar: energia para o Desenvolvimento Sustentável. 1 ed. Rio de Janeiro: 2008.

BRASIL. Decreto 19.717 de 20 de fevereiro de 1931. Estabelece a aquisição obrigatória de álcool, na proporção de $5 \%$ da gasolina importada, e dá outras providências. Rio de Janeiro, 20 de fevereiro de 1931.

Decreto 22.789 de 1 de junho de 1933. Crea o Instituto do Assucar e do Alcool e dá outras providências. Rio de Janeiro, 1 de junho de 1933.

. Decreto Lei 9.827 de 10 de setembro de 1946. Dispõe sobre a produção açucareira e dá outras providências. Rio de Janeiro, 10 de setembro de 1946.

Decreto 76.593 de 14 de novembro de 1975. Institui o Programa Nacional do Álcool e dá outras Providências. Brasília, 14 de novembro de 1975.

Decreto 83.700 de 5 de julho de 1979. Dispõe sobre a execução do Programa Nacional do Álcool, cria o Conselho Nacional do Álcool - CNAL, a Comissão Executiva Nacional do Álcool - CENAL, e dá outras Providências. Brasília, 5 de julho de 1979.

Decreto de 27 de outubro de 1993. Constitui, no âmbito do Ministério de Minas e Energia, a Comissão Interministerial do Álcool (Cinal), e dá outras providências. Brasília, 27 de outubro de 1993.

Decreto de 12 de setembro de 1995. Transfere para o âmbito do Ministério da Indústria, do Comércio e do Turismo a Comissão Interministerial do Álcool (Cinal), e dá outras providências. Brasília, 12 de setembro de 1995.

Decreto 5.652 de 21 de agosto de 1997. Cria o Conselho Interministerial do Açúcar e do Álcool - CIMA, e dá outras providências. Brasília, 21 de agosto de 1997.

Lei 9.478 de 6 de agosto de 1997. Dispõe sobre a política energética nacional, as atividades relativas ao monopólio do petróleo, institui o Conselho Nacional de Política Energética e a Agência Nacional do Petróleo e dá outras providências. Brasília, 6 de agosto de 1997. 1997a. 
Decreto 3.520 de 21 de junho de 2000. Dispõe sobre a estrutura e o funcionamento do Conselho Nacional de Política Energética - CNPE e dá outras providências. Brasília, 21 de junho de 2000.

Decreto 3.546 de 17 de julho de 2000. Cria o Conselho Interministerial do Açúcar e do Álcool - CIMA e dá outras providências.. Brasília, 17 de julho de 2000. 2000a.

Lei 11.097 de 13 de janeiro de 2005. Dispõe sobre a introdução do biodiesel na matriz energética brasileira; altera as Leis nos 9.478, de 6 de agosto de 1997, 9.847, de 26 de outubro de 1999 e 10.636, de 30 de dezembro de 2002; e dá outras providências. Brasília, 13 de janeiro de 2005.

Lei 11.116 de 18 de maio de 2005. Dispõe sobre o Registro Especial, na Secretaria da Receita Federal do Ministério da Fazenda, de produtor ou importador de biodiesel e sobre a incidência da Contribuição para o PIS/Pasep e da Cofins sobre as receitas decorrentes da venda desse produto; e dá outras providências. Brasília, 13 de janeiro de 2005, 2005a.

Decreto 5.793 de 29 de maio de 2006. Altera dispositivos do Decreto no 3.520, de 21 de junho de 2000, que dispõe sobre a estrutura e o funcionamento do Conselho Nacional de Política Energética - CNPE. Brasília, 29 de maio de 2006.

Decreto 6.685 de 10 de dezembro de 2008. Dá nova redação aos arts. 2 o e 4 o do Decreto no 3.520 , de 21 de junho de 2000, que dispõe sobre a estrutura e o funcionamento do Conselho Nacional de Política Energética - CNPE, e dá outras providências. Brasília, 10 de dezembro de 2008.

Agroindústria canavieira : ementário nacional : compêndio histórico de normativos e documentos legais. Brasília: Ministério da Agricultura, Pecuária e Abastecimento, 2009.

Medida Provisória 532 de 28 de abril de 2011. Acresce e dá nova redação a dispositivos das Leis nos 9.478 , de 6 de agosto de 1997, e 9.847, de 26 de outubro de 1999, e dá outras providências. Brasília, 28 de abril de 2011.

. Lei 12.490 de 16 de setembro de 2011. Altera as Leis nos 9.478, de 6 de agosto de 1997, e 9.847, de 26 de outubro de 1999, que dispõem sobre a política e a fiscalização das atividades relativas ao abastecimento nacional de combustíveis, e dá outras providências. Brasília, 16 de setembro de 2011, 2011a.

. Portaria 678 de 31 de Agosto de 2011. Ministério de Agricultura Pecuária e Abastecimento. Brasília, 31 de agosto de 2011, 2011b.

. Boletim Mensal dos Combustíveis Renováveis. Brasília. Ministério de Minas e Energia. Secretaria de Petróleo, Gás Natural e Combustíveis Renováveis. Departamento de Combustíveis Renováveis. Edição n. 45, 2011c.

Programa Nacional de produção e uso de Biodiesel. Brasília: Ministério de Minas e Energia. Disponível em: <http://www.mme.gov.br/programas/biodiesel/menu/programa/estrutura_gerencial.html>, 2011d.

ALICEWEB: Sistema de Análise das Informações de Comércio Exterior. Secretaria de Comércio Exterior. Sistema Integrado de Comércio Exterior (SISCOMEX). Brasília: Ministério do Desenvolvimento, Indústria e Comércio Exterior. Disponível em: <http://aliceweb2.mdic.gov.br/index/home>. Acesso em: 25 mai. 2012.

Boletim Mensal Dos Combustíveis Renováveis. Brasília. Ministério de Minas e Energia. Secretaria de Petróleo, Gás Natural e Combustíveis Renováveis. Departamento de Combustíveis Renováveis. Edição n. 52, 2012a.

CALMON, P.. Redes e governança das políticas públicas. Brasília, 2010.

CASTELLS, M.. Hacia el Estado Red?: globalizacion economica e instituciones politicas en la era de la información. Sao Paulo: Ministério da Administração Federal e Reforma do Estado, 1998.

CGEE. Estudo prospectivo de solo, clima e impacto ambiental para o cultivo da cana-de-açúcar e análise técnica/econômica para o uso do etanol como combustível: Etanol Fase 3. Campinas: Nipe/Unicamp e Centro de Gestão de Estudos Estratégicos, 2007.

CHESNAIS, F.. Competitivité technologique en tant que compétitivité structurelle. In: CHESNAIS, F.. Competitivité technologique en tant que compétitivité structurelle. Paris: Economica, 1990.

ESSER, K.; HILLEBRAND, W.; MESSNER, D.. Competitividad sistémica : Nuevo desafío a las empresas y a la política. Revista de la CEPAL, Santiago, n.59, p.39-52, 1996.

FERRAZ, J. C.; KUPFER, D.; HAUGUENAUER, L.. Made in Brazil: desafios competitivos para a indústria brasileira. Rio de Janeiro: Campus, 1997.

FLICK, U.. Introdução à pesquisa qualitativa. 3 ed. Porto Alegre: Artmed, 2009. 
GOLDEMBERG, J.; MONACO, L. C.; MACEDO, I. C.. The Brazilian Fuel-Alcohol Program. In: JOHANSSON, T. B. et al.. Renewable energy: sources for fuels and electricity. Washington: Island Press, 1993.

KEOHANE, R. O.; VICTOR, D. G.. The Regime Complex for Climate Change. Perspectives on Politics, Cambridge, n.9, p.7-23, 2011. DOI: http://dx.doi.org/10.1017/S1537592710004068

KRUGMAN, P.. El internacionalismo moderno: la economía internacional y las mentiras de la competitividad. Barcelona, Crítica-Grijalbo Mondadori, 1997.

LABRA, M. E.. Análise de políticas, modos de policy-making e intermediação de interesses: uma revisão. Physis: Revista de Saúde Coletiva, Rio de Janeiro, v.9, n.2, 1999.

MAHONEY, J.; THELEN, K.. A theory of gradual institutional change. In: MAHONEY, J.; THELEN, K.. Explaining institutional change: ambiguity, agency, and power. Cambridge: Cambridge University Press, p. 1-37, 2010.

MARCH, J. G.. Como as decisões realmente acontecem: princípios de tomada de decisões. São Paulo: Leopardo, 2009.

MARINI, C.; MARTINS, H.. Um governo matricial: estruturas em rede para geração de resultados de desenvolvimento. In: CONGRESO INTERNACIONAL DEL CLAD SOBRE LA REFORMA DEL ESTADO Y DE LA ADMINISTRACIÓN PÚBLICA, 9. Anais. 2004.

MAYNTZ, R. Modernization and the Logic of Interorganizational Networks, In: CHILD, J. et al. Societal change between market and organization. Aldershot: Avebury, 1993, p. 3-18.

MESSNER, D.; MEYER-STAMER, J.. Competitividad sistémica. Pautas de gobierno y desarrollo. Nueva Sociedad, Buenos Aires, n. 133, 1994, p. 72-87.

MORGAN, G.. Images of organization. Sage Publications. Newbury Park, CA. 1997

MILANEZ, A. Y.; NYKO, D.; LUIZ, J.; GARCIA, F.. O déficit de produção de etanol no Brasil entre 2012 e 2015 : determinantes, consequências e sugestões de política. BNDES Setorial, Rio de Janeiro, v.35, p.277-302, 2012.

QUEIROZ, G.. Vai e vem do etanol. ISTOÉ Dinheiro. Disponível:

<http://www.istoedinheiro.com.br/noticias/72000_VAl+E+VEM+DO+ETANOL>. Acesso> 16 jul 2012.

SABATIER, P. A.; WEIBLE, C. M.. The advocacy coalition framework: Innovations and clarifications. In: SABATIER, P.. Theories of the policy process. California: University of California, Westview Press, 2007, p.189-220.

SCANDIFFIO, M. I. G.. Análise prospectiva do álcool combustível no Brasil: cenários 2004-2024. Campinas: Universidade Estadual de Campinas, 2005.

SCHNEIDER, V.. Redes de políticas públicas e a condução de sociedades complexas. Civitas - Revista de Ciências Sociais, Porto Alegre, v.5, n.1, p.29-58, 2005.

STREECK, W.; THELEN, K.. Introduction: institutional change in advanced political economies. In: Beyond Continuity: institutional change in advanced political economies. Oxford: Oxford University Press, 2005. p.1-39.

THELEN, K.. Historical Institutionalism in Comparative Politics. Annual Review of Political Science, Palo Alto, v.2, n.1, p.369-404, 1999. DOI: http://dx.doi.org/10.1146/annurev.polisci.2.1.369

TRUE, J. L.; JONES, B.; BAUGARTNER, F.. Punctuated-Equilibrium Theory: explaining stability and change in public policy making. In: SABATIER, P. A.. Theories of the Policy Process. Boulder: Westview Press, 2007. p.155-187.

TYSON, L. D.. Who's bashing whom: trade conflict in high technology industries. Washigton: Institute for International Economics, 1992.

UDOP. Cana-de-açúcar: Linha do tempo. 2007. Disponível:

<http://www.udop.com.br/index.php?cod=75181\&item=noticias\#nc>. Acesso: 15 jul. 2012. 